\title{
Cryopreservation of Xenopus Sperm and In Vitro Fertilization Using Frozen Sperm Samples
}

\author{
Anna Noble, Anita Abu-Daya, and Matt Guille ${ }^{1}$ \\ European Xenopus Research Center (EXRC), School of Biological Sciences, University of Portsmouth, Portsmouth \\ PO1 2UP, United Kingdom
}

The cryopreservation of Xenopus sperm allows for a significant reduction of the number of animals that must be kept, more efficient archiving of genetically altered (GA) lines, and easy exchange of lines with other laboratories, leading to improvements in animal welfare and cost efficiency. In this protocol, sperm from Xenopus laevis or Xenopus tropicalis are frozen using straightforward techniques and standard laboratory equipment. Testes are macerated in Leibovitz's L-15 medium, mixed with a simple cryoprotectant made from egg yolk and sucrose, and frozen slowly overnight in a polystyrene box at $-80^{\circ} \mathrm{C}$. Unlike mouse sperm, Xenopus sperm can be stored at $-80^{\circ} \mathrm{C}$ rather than in liquid nitrogen, further reducing costs. The frozen sperm are then used for in vitro fertilization.

Reagents

It is essential that you consult the appropriate Material Safety Data Sheets and your institution's Environmental Health and Safety Office for proper handling of equipment and hazardous materials used in this protocol.

RECIPES: Please see the end of this protocol for recipes indicated by $<\mathrm{R}>$. Additional recipes can be found online at http://cshprotocols.cshlp.org/site/recipes.

Cryoprotectant solution $<\mathrm{R}>$, ice-cold

L-15 supplemented with 10\% FBS and 2 mM L-glutamine $<\mathrm{R}>$, freshly prepared and on ice

Modified Barth's saline (MBS) $(1 \times, \mathrm{pH} 7.8)<\mathrm{R}>$ or Marc's modified Ringer's (MMR) $(1 \times)<\mathrm{R}>$, diluted to $0.1 \times$ and supplemented with $1 \mathrm{~mL} / \mathrm{L}$ penicillin-streptomycin solution (Sigma-Aldrich P4458)

Unsupplemented L-15 (Sigma-Aldrich L5520) or MBS (1×, pH 7.8) (optional; see Step 1)

Xenopus laevis or Xenopus tropicalis adult males and females

Equipment

Aluminum foil

Cardboard CryoBox (e.g., $136 \times 136 \times 32$ mm [Fisher]) (optional; see Step 6)

Dissecting microscope

${ }^{1}$ Correspondence: matthew.guille@port.ac.uk

From the Xenopus collection, edited by Hazel L. Sive.

(C) 2022 Cold Spring Harbor Laboratory Press

Cite this protocol as Cold Spring Harb Protoc; doi:10.1101/pdb.prot107029 
Filter tips (200- $\mu$ L, large-orifice [e.g., Fisher Scientific 11947744] or with $\sim 2 \mathrm{~mm}$ of the ends cut off) Using large-orifice tips or cutting the ends off of standard filter tips is essential to eliminate mechanical shearing damage to the sperm.

Incubator set at $18^{\circ} \mathrm{C}$ for $X$. laevis or at $23^{\circ} \mathrm{C}$ for $X$. tropicalis

Liquid nitrogen (optional; see Step 7)

Microcentrifuge tubes (1.5-mL [optional; see Step 4] and 2-mL)

Paper towels

Pellet pestles (optional; see Step 4)

Petri dishes (60-mm and 90-mm)

Pipette tips (1-mL, with the ends cut off)

Polystyrene box (external measurements: $\sim 23 \times 23 \times 27 \mathrm{~cm}$; thickness of the wall: $4 \mathrm{~cm}$ )

Thin-walled PCR tubes (0.5-mL; e.g., ThermoFisher Scientific AB-0350)

Tubes (30-mL) (optional; see Step 2)

Tweezers (forceps)

Water bath at $37^{\circ} \mathrm{C}$

\section{METHOD}

This protocol was adapted from the method initially developed by Sargent and Mohun (2005), with further amendments by the EXRC and NXR (Pearl et al. 2017).

Use the same volume of reagents for all procedures regardless of species (X. laevis or X. tropicalis).

Freezing Sperm

1. Euthanize the male frog(s) painlessly according to local regulations and remove testes as in Protocol: Obtaining Xenopus laevis Embryos (Shaidani et al. 2021) or Protocol: Obtaining Xenopus tropicalis Embryos by In Vitro Fertilization (Lane and Khokha 2021). Use tweezers to carefully remove any blood vessels and excess fat tissue. Roll the testes on paper towels to remove all traces of blood.

$\mathrm{X}$. laevis testes can be stored in $1 \times$ MBS or in L-15 (unsupplemented) for up to 1 wk at $4^{\circ} \mathrm{C}$, but X. tropicalis sperm should be frozen immediately because success of freezing diminishes rapidly over time.

2. For each pair of testes, place $1 \mathrm{~mL}$ of ice-cold cryoprotectant solution in a 2 -mL tube and leave on ice.

Testes from 2-6 males can be pooled per batch. If pooling, scale up Steps 2-5 as necessary and use 30-mL tubes.

3. Label $16500-\mu \mathrm{L}$ thin-walled PCR tubes, and place them in a rack ready for rapid filling. Eight samples of $125 \mu \mathrm{L}$ per testis will be frozen (16 samples per male).

4. Transfer testes to a 6-mm Petri dish placed at a $45^{\circ}$ angle with $1 \mathrm{~mL}$ of L-15 medium supplemented with FBS and L-glutamine, and carefully macerate the testes with tweezers.

$\mathrm{X}$. tropicalis testes can be transferred to a microcentrifuge tube containing $0.5 \mathrm{~mL}$ of L-15 supplemented with FBS and l-glutamine and macerated gently using a plastic disposable pestle made for use in Eppendorf tubes. Once the testes are homogenized, add an additional $0.5 \mathrm{~mL}$ of ice-cold, supplemented L15 medium. Macerating X. laevis testes with pellet pestle is not recommended. We saw very low sperm recovery compared to maceration with the tweezers.

5. Transfer the sperm suspension using a 1-mL tip with a cut end to the $2-\mathrm{mL}$ tube containing $1 \mathrm{~mL}$ of cryoprotectant on ice. Gently mix the contents by inversion.

6. With a cut-off pipette tip or a large-orifice $200-\mu \mathrm{L}$ filter tip, transfer $125-\mu \mathrm{L}$ aliquots of the sperm into the prepared tubes. Immediately place the samples in a polystyrene box and cover with aluminum foil (instead of the normal lid). Place the box in a $-80^{\circ} \mathrm{C}$ freezer. 
A. Noble et al.

\begin{abstract}
In total, 96 tubes (sperm from six frogs) can be put in a polystyrene box in any one round of freezing. For larger numbers of aliquots, racking the sperm samples in cardboard CryoBoxes within the polystyrene box makes it easier to transfer them to long-term storage and has the advantage of ensuring the sperm suspension is at the bottom of all the tubes.

Aim to get the samples into the $-80^{\circ} \mathrm{C}$ freezer as fast as possible. We can get 96 aliquots of sperm into the freezer in $<10 \mathrm{~min}$ from the maceration. Label all the tubes and organize them in racks at room temperature in advance.
\end{abstract}

7. The next day, move the samples from the polystyrene box into long-term storage at $-80^{\circ} \mathrm{C}$.

Samples can be also be successfully frozen in cryotubes and stored in liquid nitrogen.

\section{In Vitro Fertilization Using Frozen Sperm}

Keep tubes with frozen sperm at $-80^{\circ} \mathrm{C}$ or on dry ice until the eggs are ready to be fertilized.

8. Extrude approximately $500 \mathrm{X}$. laevis or X. tropicalis eggs into a dry $90-\mathrm{mm}$ Petri dish as described in Protocol: Obtaining Xenopus laevis Embryos (Shaidani et al. 2021) or in Protocol: Obtaining Xenopus tropicalis Eggs (Lane et al. 2021). Check egg quality under a dissecting microscope as there is no point wasting frozen sperm on poor-quality eggs.

If you are using valuable GA sperm, we recommend testing the first batch of eggs produced on the fertilization day by fertilizing with fresh sperm so that precious frozen samples are not wasted.

9. Thaw frozen sperm in a water bath for $30 \mathrm{sec}$ at $37^{\circ} \mathrm{C}$ by moving it in a figure 8 until most of the frozen sperm has thawed.

10. Immediately add $250 \mu \mathrm{L}$ of $0.1 \times$ MBS or $0.1 \times$ MMR to the $125-\mu \mathrm{L}$ sperm sample, and mix gently by pipetting up and down five to10 times using large-orifice or cut-off pipette tips.

11. As quickly as possible, using the same tip, apply the sperm suspension to the eggs and mix gently. Spread the eggs into a monolayer with a pair of fresh, uncut, $200-\mu \mathrm{L}$ pipette tips. Make sure all eggs are covered by the sperm and place the lid on the Petri dish. Incubate the dish at $18^{\circ} \mathrm{C}$ for $X$. laevis or at $23^{\circ} \mathrm{C}$ for $X$. tropicalis.

12. After $5-10 \mathrm{~min}$, flood the eggs with $0.1 \times$ MBS or $0.1 \times$ MMR. Incubate the dish at $18^{\circ} \mathrm{C}$ for $X$. laevis or at $23^{\circ} \mathrm{C}$ for $X$. tropicalis.

13. Within $2 \mathrm{~h}$, estimate the fertilization rate by comparing divided to undivided eggs.

See Troubleshooting.

14. Culture the embryos as described in Protocol: Obtaining Xenopus laevis Embryos (Shaidani et al. 2021) or Protocol: Obtaining Xenopus tropicalis Embryos by In vitro Fertilization (Lane and Khokha 2021), changing the medium on a daily basis.

Problem (Step 13): The fertilization rate is low.

Solution: Successful fertilization following sperm cryopreservation occurs more robustly in $X$. tropicalis than in X. laevis (Pearl et al. 2017). In the latter species, results are more inconsistent between individual frogs, possibly because of variations in sexual maturity and differing health of animals. However, it is possible to successfully freeze sperm from both species. X. laevis males can be primed with 35-50 IU of PMSG 3-5 d before harvesting testes to improve sperm maturity, but this does not appear to improve $X$. tropicalis sperm. See Protocol: Obtaining Xenopus laevis Embryos (Shaidani et al. 2021) for information on priming frogs. 
In addition, consider the following.

- If you are recovering a GA line, consider pooling eggs from different females into one Petri dish in Step 8 to increase the success of fertilization, which may be compromised by a lack of biological compatibility.

- Be consistent in Step 10. Too many or too few pipetting actions seems to be an area in which inconsistent success arises.

- Before adding the sperm suspension in Step 11, make sure that the eggs are not in any liquid. If during egg extrusion some liquid drops to the Petri dish, blot it off with a paper towel.

- In our hands, collecting eggs in high-salt solution did not result in fertilization using frozen sperm.

\section{Cryoprotectant Solution}

1. Disperse one chicken egg's yolk ( $\sim 15-\mathrm{mL}$; preferably organic) in an equal volume of molecular biology grade water to make Solution A. Mix by pipetting up and down.

2. Combine the following reagents and bring to $1000 \mathrm{~mL}$ to make Solution $\mathrm{B}$, which consists of $0.4 \mathrm{~m}$ sucrose, $10 \mathrm{~mm} \mathrm{NaHCO}_{3}, 2 \mathrm{~mm}$ pentoxyfilline.

$\begin{array}{lr}\text { Sucrose } & 136.92 \mathrm{~g} \\ \mathrm{NaHCO}_{3} & 0.84 \mathrm{~g} \\ \text { Pentoxyfilline (Sigma-Aldrich P1784) } & 0.56 \mathrm{~g}\end{array}$

3. Dilute Solution A to $20 \% \mathrm{v} / \mathrm{v}$ in Solution B by adding $10 \mathrm{~mL}$ of Solution A to $40 \mathrm{~mL}$ of Solution B. Divide the mixture into two $30-\mathrm{mL}$ centrifuge tubes and centrifuge at $10,000 \mathrm{~g}$ in a Beckman Allegra 25R Refrigerated Centrifuge with a TA-14-50 rotor or equivalent for $20 \mathrm{~min}$ at $10^{\circ} \mathrm{C}$. Discard pellets. For immediate use, store on ice. Store the rest as 1 - or $5-\mathrm{mL}$ aliquots for up to $1 \mathrm{yr}$ at $-20^{\circ} \mathrm{C}$.

\section{L-15 Supplemented with 10\% FBS and 2 mm L-glutamine}

Reagent Volume

L-15 medium (Sigma-Aldrich L5520)

$9 \mathrm{~mL}$

Fetal bovine serum (FBS) (Sigma-Aldrich F9665)

$1 \mathrm{~mL}$

L-glutamine $200 \mathrm{~mm}$ (Sigma-Aldrich G7513)

$10 \mu \mathrm{L}$

Store $100-\mu \mathrm{L}$ aliquots of $200 \mathrm{mM} \mathrm{L}$-glutamine and $1-\mathrm{mL}$ aliquots of $\mathrm{FBS}$ at $-20^{\circ} \mathrm{C}$ and use them to supplement L15 media on the day of sperm cryopreservation. (L-glutamine solutions degrade relatively rapidly, although the powder form is very stable.)

Marc's Modified Ringer's (MMR) (1X)

$0.1 \mathrm{M} \mathrm{NaCl}$

$2 \mathrm{~mm} \mathrm{KCl}$

$1 \mathrm{mM} \mathrm{MgSO}_{4}$

$2 \mathrm{mM} \mathrm{CaCl}_{2}$

5 mM HEPES (pH 7.8)

0.1 mм EDTA

Sterilize by autoclaving, and store at room temperature.

Common alternative formulations of MMR omit EDTA and are adjusted to $\mathrm{pH}$ 7.4. 
A. Noble et al.

Modified Barth's Saline (MBS) (1×, pH 7.8)

\begin{tabular}{lcc} 
Reagent & Quantity (for 1 L) & Final concentration $(1 \times)$ \\
\hline $\mathrm{NaCl}$ & $5.143 \mathrm{~g}$ & $88 \mathrm{~mm}$ \\
$\mathrm{KCl}$ & $0.075 \mathrm{~g}$ & $1 \mathrm{~mm}$ \\
$\mathrm{MgSO}_{4}$ & $0.120 \mathrm{~g}$ & $1 \mathrm{~mm}$ \\
$\mathrm{HEPES}$ & $1.192 \mathrm{~g}$ & $5 \mathrm{~mm}$ \\
$\mathrm{NaHCO}_{3}$ & $0.210 \mathrm{~g}$ & $2.5 \mathrm{~mm}$ \\
$\mathrm{CaCl}_{2}$, dihydrate & $0.103 \mathrm{~g}$ & $0.7 \mathrm{~mm}$ \\
$\mathrm{H}_{2} \mathrm{O}$ & to $1 \mathrm{~L}$ &
\end{tabular}

Adjust the $\mathrm{pH}$ to 7.8 with $10 \mathrm{M} \mathrm{NaOH}$ and sterilize by autoclaving. Store at room temperature indefinitely.

\section{REFERENCES}

Lane MA, Khokha MK. 2021. Obtaining Xenopus tropicalis embryos by in vitro fertilization. Cold Spring Harb Protoc doi: 10.1101/pdb.prot106351

Lane MA, Mis EK, Khokha MK. 2021. Obtaining Xenopus tropicalis eggs. Cold Spring Harb Protoc doi: 10.1101/pdb.prot 106344

Pearl EJ, Morrow S, Noble AM, Lerebours A, Horb ME, Guille M. 2017. An optimized method for cryogenic storage of Xenopus sperm to maximise the effectiveness of research using genetically altered frogs. Theriogenology 92: 149-155. doi:10.1016/j.theriogenology.2017.01.007

Sargent MG, Mohun TJ. 2005. Cryopreservation of sperm of Xenopus laevis and Xenopus tropicalis. Genesis 41: 41-46. doi:10.1002/gene.20092

Shaidani N-I, McNamara S, Wlizla M, Horb ME. 2021. Obtaining Xenopus laevis embryos. Cold Spring Harb Protoc doi: 10.1101/pdb.prot106211 


\section{Cryopreservation of Xenopus Sperm and In Vitro Fertilization Using Frozen Sperm Samples}

Anna Noble, Anita Abu-Daya and Matt Guille

Cold Spring Harb Protoc; doi: 10.1101/pdb.prot107029 originally published online September 16, 2021

\begin{tabular}{rc}
$\begin{array}{r}\text { Email Alerting } \\
\text { Service }\end{array}$ & Receive free email alerts when new articles cite this article - click here. \\
\hline $\begin{array}{c}\text { Subject } \\
\text { Categories }\end{array}$ & $\begin{array}{c}\text { Browse articles on similar topics from Cold Spring Harbor Protocols. } \\
\text { Developmental Biology (728 articles) } \\
\text { Genetics, general (375 articles) } \\
\text { Xenopus (210 articles) } \\
\text { Xenopus Transgenics (32 articles) }\end{array}$ \\
\hline
\end{tabular}

